\title{
SEEING YOURSELF IN A NEW LIGHT: CROSSING THRESHOLDS IN BECOMING A RESEARCHER
}

\section{Sherran Clarence}

\section{INTRODUCTION}

Undertaking doctoral study is a transformative act. Doctoral students develop from "becoming-researchers" to scholars through the process of researching and writing. The transformation of the novice doctoral scholar into a capable, confident and independent researcher is a process, often fraught and challenging, that asks such candidates to cross many thresholds. You primarily think your way through your study, and it is the changes in the way you think and what you think about that hold the greatest transformative potential for you as a "becoming-researcher". Transformation - change - is tough, but almost always worth the effort. Aitchison and Mowbray (2013), Barnacle and Mewburn (2010), Mewburn (2011) and Barnacle (2005) have written about the emotional, personal and identity-related challenges that those undertaking doctoral study encounter. What their work highlight, in relation to this chapter, is that a doctorate is not just a qualification alone, and a thesis is not just something we write to get a qualification. Undertaking doctoral study changes the way we think about ourselves, our research and the world around us. The process, in all its struggles, triumphs and challenges, transforms us into something other than what and who we were when we started out, and this is not an easy or comfortable process. It must, therefore, be something that, as a postgraduate student, you ultimately want, even if you do not know exactly what you are getting into when you start out.

In this chapter, I reflect on the emotional or identity shifts that I felt happening within me as I crossed three key thresholds in my journey from a "becoming-researcher" to a full-fledged researcher. As I crossed these three thresholds, my conceptions of my own researcher identity changed, in profound ways, and the way I viewed my research changed too. In what follows, I will look critically at my own research 


\section{POSTGRADUATE STUDY IN SOUTH AFRICA}

journal and blog writings, and offer some useful insights into how doing a PhD, or indeed any significant postgraduate research project, can enable a new way of seeing yourself as a "becoming-researcher", and related career possibilities.

\section{THREE THRESHOLDS TO CROSS}

I reflect on three thresholds I crossed during my PhD by drawing on the work of Kiley (2009), and Kiley and Wisker (2009). They adapt and use as an analytical tool Meyer and Land's (2005) threshold concepts, with Turner's (1979) concept of liminality. Essentially, a threshold is a doorway into a new space. Crossing a threshold changes the way you understand the concept and its relationship to other concepts, theories or problems, as well as the way you see your research and/or yourself in relation to the world around you (Meyer \& Land 2005). The key to understanding a threshold concept is that you cannot "unsee" once you have seen, and although the threshold concept will not uncover all the relationships of the whole, crossing one threshold enables you to cross further conceptual, epistemological and ontological thresholds as you progress (Kiley 2009). Threshold crossing is thus transformative (Land 2014) - it changes you as a scholar, as a researcher and as a person.

Kiley and Wisker (2009) and Kiley (2009) connect the concept of thresholds with that of liminality - thus dealing with uncertainty while being transformed (drawn from Turner 1979). Turner describes three stages in a transformative process: separation, where you have to move away from what you already know or believe; margin or limen, where you are in a liminal space between not knowing and knowing; and aggregation, where you are transformed as the threshold is crossed and new understanding or clarity is achieved. Liminal spaces tend to be uncertain in nature; you feel that you are on the cusp of change, but even if that change is welcome you do not always know what is on the other side, and what you will have to leave behind in order to move forward. Moving through a PhD involves moving across thresholds, through liminal spaces of uncertainty, anxiety and sometimes fear. Liminality is part of the journey, perhaps the most challenging part. Change and transformation are difficult processes, as they require us not only to gain something, but also often to leave something behind - ideas we have long cherished, or a way of seeing the world we have become comfortable with, for example (Land 2014).

The following sections outline three major thresholds I crossed during my PhD, and how they changed the way I saw myself as a researcher in terms of my changing scholarly identity. These thresholds involved acts of writing - either formal (such as chapter drafts) or informal (for example, field notes and research journaling) - and these three points mark significant shifts in many PhD scholars' endeavours. 


\section{Designing your "Theoryology": A house can only stand on firm foundations}

"Theoryology" is a term I created during my PhD to help me understand what I was creating in my theoretical and conceptual framework - one of the key threshold concepts Kiley and Wisker's (2009) research identified as being challenging for PhD scholars. This was the most challenging part of thinking and writing my thesis as I really had no idea what this kind of framework was in the abstract, how to build one for my own study, and what to actually do with it once built.

I spent the better part of a year working on the theory chapter. It was a year in which I wrote several drafts, trying to find my voice and build a framework that would enable me to take the next steps into methodology and data analysis. It was frustrating in large parts because it did not really feel like I was doing very much. Taking a whole year out of three years in total to work on one chapter (out of six or seven chapters) seemed overly indulgent, and dangerously slow. I was, for a long time, in a series of smaller liminal spaces around my theoretical concepts, knowing something and then losing it again, letting go of older understandings as newer meanings made more sense to me. I was also in a larger liminal space around this bigger threshold of finally having a conceptual framework, and having my gaze become clearer as I moved forward in my research.

I can track a small sense of shifting in three entries taken from my research journal, all written in 2012 (the theory year).

No real sense of how the theoretical bits I am writing will blend into a coherent structure yet, but this is as far as my headlights are reaching right now (11 May 2012).

To:

I am restructuring, building, rethinking my framework - I feel like this process will go on for a while yet! (9 August 2012).

And then to:

The BIG thing I need now, for me to feel like I'm on top of this, is to find examples that will explain all of this dense + complex theory or pictures, or both. I'm feeling a little more clear and a little more lost. (22 September 2012).

What these comments indicate to me now, looking back, is a sense of a non-linear and layered writing and thinking process, and a sense of my own ideas and thinking changing along the way. From May to August there is a sense that I had new insights into the connections between the concepts I was using and how they fitted into the framework, necessitating rethinking and restructuring. In August, compared to May, 
I sounded a little more confident in my sense of creating something more coherent, indicating that I was starting to see how things were fitting together. By September, I had worked out a fairly coherent structure, and needed examples to illustrate the theory to readers so that they would understand how I was using it all and why.

The comment about being both lost and found is how I felt throughout most of my PhD journey. As I found my way to something new, I felt like I lost my grip a little on something else, especially when I had to move away from the theory for a while to generate my data. This feeling of being lost and found and then lost again signals, I believe, movement through liminal spaces from one side of this threshold to the other. This image I drew (on 9 August 2012) represents the cyclical, but progressive thinking and writing process that I felt was pushing me over thresholds - from being a novice researcher, to becoming a less novice researcher over time. Each point or arrow in the spiral is a theoretical or conceptual threshold crossed, slowly moving me towards the centre - a clearer, tighter account of what my study was about ${ }^{l}$.

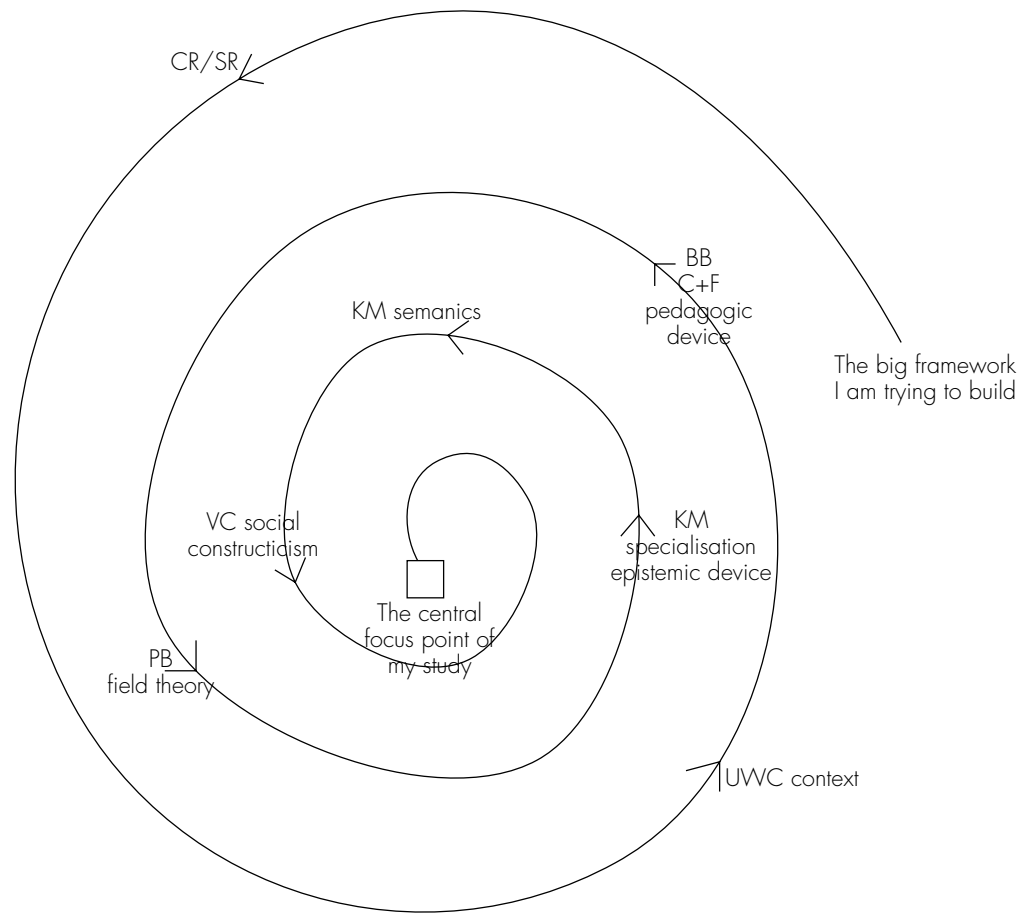

FIG 11.1. Pushing thresholds

1 This image seems in a way similar to Catherine Robertson's progression towards her conceptual framework (see Chapter 13 of this book). 
Towards the end of the year I wrote, "I have too much theory" but then a day later, after a conversation with a colleague, I wrote,

No theory pruning yet. Leave what is there, hone, refine and finish, and move on. Prune later. Need data first. (29 October 2012)

I did not really feel completely ready at that point to generate data, but I knew I had to move on from the theory. I had sufficiently crossed theoretical and conceptual thresholds such that I had a gaze - I had a way of looking at the part of the world my research was interested in, and I needed to start looking at it. I needed to move beyond the theory thresholds towards the next set of thresholds and liminal spaces: the field, and the generation, organisation and analysis of my data. In the South African context, within the social sciences and humanities, most postgraduate research seems to require students to immerse themselves in reading, both their field and theory, to find and firm up their research questions and a focus for the study, before the study itself can be enacted. If you are working in this way, you may find yourself at this threshold feeling similarly hesitant: with a tenuous gaze that needs to be further tested, refined and developed through getting stuck into your study, whether this includes fieldwork, archival work or other forms of empirical research.

\section{Moving into the field: Out of the theory clouds into the data swamp}

For any researcher who has never really done an empirical study before, the step that moves you from theory to data can be a big and intimidating one. But as thresholds go, this is a vital one to cross in terms of your development and growth as a researcher. It is another of the threshold concepts identified as being a potential stumbling point for doctoral students (Kiley \& Wisker 2009).

Bernstein (2000) argued that theory and empirical data have an important and necessary relationship: theory informs the generation of empirical data, but empirical data, in turn, speaks back to and can reshape, challenge or push the theory in new ways. They have a dialectical relationship, and one that should not be underestimated. Without data, theory is rather meaningless (and without theory, data is just information). This threshold, then, is important on two levels: on the first level, it moves your study from going around in circles telling yourself what you probably already know about the theory in an abstract way towards making sense of the theory in empirical contexts that speak back to it, situate it, and bring it to life. On the second level, it moves you as a researcher from seeing yourself as being a researcher in a more abstract, perhaps "bookish" sense to actually doing the role of researcher in a more physical, active sense. 


\section{POSTGRADUATE STUDY IN SOUTH AFRICA}

I had never felt like a "proper" researcher before I did my PhD. I had not designed a study, put it into practice and seen it through from beginning to end. My Master's research project was a policy analysis, and all my data were documents. I had done a small empirical study before I started my PhD, but I did not really feel like I knew what I was doing in terms of research design or data generation, and I certainly did not understand the connections between theory and data, and the need for a "theoryology" that would influence what data I would generate and how I would analyse it. The liminal space around this threshold was a lonely one for me, in spite of my supervisor's support. I had to go out into the field on my own, and I had to work out how to connect the data, once generated, back to my "theoryology" in a relevant dialectical and generative way.

Excerpts from my research journal attest to some of the struggles and also moments of realisation in making my way across this particular threshold in my $\mathrm{PhD}$ :

I need to think a bit about ... what is theory? Clearly [my framework] is influencing my choices, but I can't just restate my 2nd chapter. What do I need to include ... to create a theoretical discussion about why I have chosen my particular research design? What is my research design? Oh dear. I have a lot of work to do here. (19 February 2013)

What is ER + SR in my data may not fit very neatly into the way these are portrayed in the theory. I will need to use the theory as a guide but then explain my analysis using my data, making it speak back to or respond to the theory. But this is good, because this is the ... language of description ... linking theory to empirical data. (17 May 2013)

Theory not being realised in the data as it looks in the theory has been quite alarming. Big thing is already seeing how $\mathrm{CH} 2$ (theory chapter) needs to be revised but also waiting until I have made more sense out of the data ... Climbing my way up data mountain - trying to avoid falling off into the valley of despair. (1 1 July 2013)

Moving from theory to data, and then eventually back again, in an iterative organisation and analysis process formed a series of smaller thresholds that, once crossed, changed me as a scholar and researcher. These excerpts show a process of realising that theory and data do not always line up perfectly to speak exactly the same dialect. The ways in which I had to create a relationship between the two in my study and show this to my readers have changed the way I see myself, as well as what I am now capable of in terms of future research. I moved closer, with each trudging crossing, to a completed $\mathrm{PhD}$ thesis, and to more fully taking on a new doctor-researcher identity. 


\section{The first draft: "It's a thesis!" (but there's work to be done)}

The final threshold is the submission of the first full draft. Until I pressed "save" and sent the first draft to my supervisor, I did not truly believe that I could finish my PhD or that I could be a researcher-doctor. I could not see my argument as a whole, or how all the pieces had come together underpinned by what Trafford and Leshem (2009:305) call "doctorateness". Doctorateness refers to a deeper ontological stance that enables the researcher to take all the parts of a $\mathrm{PhD}$ and create a thesis that is more than the sum of its parts, and that makes a contribution to knowledge in its field.

A PhD is written in chunks, bursts and multiple drafts. It takes its form slowly, and this bit-by-bit way of writing and thinking means that it can be very difficult to see the wood from the trees, as it were, in terms of the transformations in yourself, or those in your writing and thinking. You cannot see that first full draft with all the bits and pieces brought together into a coherent whole, because all you really see are the bits and pieces.

One of the most challenging parts of producing the first full draft was the revisions that came after I submitted it. This was a painful threshold for me, full of self-doubt and worry about the quality of my work. But it brought about further shifts in my thinking, and in my subjectivity as a scholar. Once I received all the feedback, I put off the revisions for as long as I could. I was just too tired to go on. At times, I longed for someone to come and cross this particular threshold - from first to examinationready draft - for me:

Revisions suck ... I am so tired now. Why can't this draft just be done? I wish I was like the cobbler in The Elves and the Shoemaker who would wake up in the morning and find that sweet little shoemaker elves had come and helped him to finish all his work because they saw how tired he was and how much he needed to get the work done. But there are no sweet little PhD-writing elves to help me. I wake up every morning and my to-do list for the revisions I have to do seems longer rather than shorter. (Blogpost, Revisions Suck, 21 September 2013)

But I also realised that if I did have someone, like my supervisor for example, to do the revisions for me - and we know from the research Clare Aitchison and others (2010) have done that this often happens - I would feel cheated. I would not have actually done the threshold-crossing myself, and could therefore not have felt, gained and also legitimately claimed the rewards I ultimately did. So, at the end of this same blogpost I wrote:

I am realising that, while some days (like today) I really wish the elves were real, I actually would feel a bit cheated if someone did this bit for 


\section{POSTGRADUATE STUDY IN SOUTH AFRICA}

me, even though it sucks. So much of this PhD-writing is more about the journey and the learning along the way than it is about the destination (Blogpost, Revisions Suck, 21 September 2013).

Getting to the point where the draft was ready to submit for examination was a long struggle - some of it thrilling and exciting, much of it difficult and exhausting as I balanced work, home, children and my PhD. Handing in the first draft was a huge threshold crossed - it transformed my sense of myself as a researcher far more than handing in the revised draft for the examination process or the final draft to the library before graduation. This was the point at which I knew that I would indeed be able to claim my new identity as a researcher, a doctor, a peer.

\section{REFLECTIONS: SEEING YOURSELF IN A NEW LIGHT}

Looking back, I think that the ways in which doing my PhD has changed me - as a writer, researcher and scholar in my field - is less about the "big book" I have written, and more about the thresholds I crossed along the way. Crossing these thresholds enabled me to experience and develop a new scholarly identity. Working in liminal spaces, where you feel you are changing in terms of the ways in which you think, read, write, speak and interact with other PhD scholars and researchers in your community can be thrilling. It can also be terrifying and filled with self-doubt, anxiety and feelings of being an imposter. But, as Land (2014) and others (Kiley \& Wisker 2009; Trafford \& Leshem 2009) argue, if we are able to push through these discomforts and worries, and challenge ourselves to look on the thresholds in whatever form they come as opportunities for transformation and growth, we will be able to see more clearly what they have to offer, instead of focussing on the struggle and giving up. We can see the potential for ourselves - intellectually and emotionally - to be different, and hopefully different to be more than what we were.

As a scholar and researcher, I am certainly different and more capable, confident and sure of myself than I was before. This self-assuredness is not always easy to hold onto in the face of challenges to my research, or new thresholds in the form of extensions and developments of that research. But the PhD has taught me that if I "trust the process", it will come. If I do the work - and I now know that I can - the project will unfold, and the thinking and writing work will yield interesting answers and new knowledge. The PhD - all those liminal, scary, anxious spaces and challenging thresholds - has transformed me into a scholar, a researcher, who believes that even when I cannot see the answers, I can work on a process that will eventually show me what these answers could be. 


\section{CONCLUSION}

This chapter offers a way to think about the research journey as a series of thresholds you can cross. If you are able to think more reflectively about the ways in which your thinking, writing and speaking about your research are changing and shiffing in relation to the thresholds you may cross, you may be able to see yourself in a new light; as more than just a student doing a PhD or Master's degree. You may see yourself as a "becoming-researcher" and therefore begin to own that identity and harness it - not only pushing you through your own liminal spaces and across uncertain thresholds, but also re-imagining your career and work prospects, and possibilities for future research and writing endeavours.

\section{REFERENCES}

Aitchison, C., Catterall, J., \& Ross, P. (2010). Learning doctoral writing: Pain and pleasure. Paper presented at the WDHE Conference, London, United Kingdom, 21-23 July 2010.

Aitchison, C., \& Mowbray, S. (2013). Doctoral women: Managing emotions, managing doctoral studies. Teaching in Higher Education, 18(8):859-870. http://dx.doi.org/10.1080/13562517.2013.827642

Barnacle, R. (2005). Research education ontologies: Exploring doctoral becoming. Higher Education, Research and Development, 24(2):179-188. http://dx.doi.org/10.1080/07294360500062995

Barnacle, R., \& Mewburn, I. (2010). Learning networks and the journey of "becoming doctor". Studies in Higher Education, 35(4):433-444. http://dx.doi.org/10.1080/03075070903131214

Bernstein, B. (2000). Pedagogy, symbolic control and identity (4th ed). New York, USA: Rowman and Littlefield, Inc.

Clarence, S. (2013, 21 September). Revisions suck [Web log post] Available online at http://wp.me/p3VNfn-e

Kiley, M. (2009). Identifying threshold concepts and proposing strategies to support doctoral education. Innovations in Education and Teaching International, 46(3):293-304. http://dx.doi.org/10.1080/14703290903069001

Kiley, M., \& Wisker, G. (2009). Threshold concepts in research education and evidence of threshold crossing. Higher Education, Research and Development, 28(4):431 -444. http://dx.doi.org/10.1080/07294360903067930

Land, R. (2014). Liminality close-up. Keynote paper presented at Higher Education Close Up (HECU) 7, Lancaster, United Kingdom, 21-23 July 2014. Available online at http://www.lancaster.ac.uk/fass/events/hecu7/docs/ThinkPieces/ land.pdf 


\section{POSTGRADUATE STUDY IN SOUTH AFRICA}

Mewburn, I. (201 1). Troubling talk: Assembling the PhD candidate. Studies in Continuing Education, 33(3):321-332. http://dx.doi.org/10.1080/0158037X.2011.585151

Meyer, J., \& Land, R. (2005). Threshold concepts and troublesome knowledge (2): Epistemological considerations and a conceptual framework for teaching and learning. Higher Education, 49(3):373-388. http://dx.doi.org/10.1007/s10734-004-6779-5

Trafford, V., \& Leshem, S. (2009). Doctorateness as a threshold concept. Innovations in Education and Teaching International, 46(3):305-316. http://dx.doi.org/10.1080/14703290903069027

Turner, V. (1979). Betwixt and between: The liminal period in rites of passage. In W. Less \& E. Vogt (Eds.). Reader in Comparative Religion (pp. 234-243). New York, USA: Harper and Row. 